\title{
Challenges Confronted by Editors of Sci-tech Journal of University and Measures in New Media Age
}

\author{
Lihua Zhao \\ Editorial Department of Journal of Jilin Agricultural University, Changchun 130118, China
}

Zhaolihua2004@126.com

Keywords: New media age; sci-tech journal; editor; brand; standardization; internationalization

\begin{abstract}
With the advent of the new media age, the channel that people obtain scientific and technical information has undergone major changes. The traditional concept of editors of sci-tech journals can not meet the developing needs of the new era under the new situation. In order to improve the comprehensive qualities and capabilities of the editors of sci-tech journals of university, increase the competitiveness of sci-tech journals and promote the development of the journals and new media convergence, this paper explains the meaning of the new media, and discusses the new requirements of the new media age for the editors of sci-tech journals of university. The editors should take the following measures to the challenges: establishing brand awareness and improving the competitiveness of journals, enhancing awareness of standardization and accelerating the internationalization, establishing a sense of further processing of information and speeding up the dissemination of scientific and technical information, establishing editors' modern awareness and improving the applying ability of the new media, enhancing business awareness and improving the benefits of journals, enhancing copyright awareness and protecting the legitimate rights and interests and strengthening exchanges and increasing the influence of journals.
\end{abstract}

\section{Introduction}

With the rapid development of science and technology, new media comes into being based on digital web. In terms of traditional media (newspaper, radio, television, etc.), new media is a communicative pattern to provide information and entertainment services to users by means of digital technology, network technology, mobile technology, the Internet, broadband local area networks, wireless communication networks and satellite etc. as well as computers, mobile phones, digital televisions, etc. for the terminal. The new media is the trend and direction of the mass media market development [1]. With the advent of the new media age, the channel that people obtain scientific information has undergone major changes, which brings the opportunity to accelerate the development of sci-tech journals of university, but it also brings challenges to the editors. The fierce competition between the journals proposes new and higher requirements for the editors of journals [2]. The quality of the editors of sci-tech journals of university is directly related to longitudinal transfer, horizontal communication and social and economic benefits of university research results so the editors should have unprecedented pressure and urgency, and their comprehensive quality and ability need to be improved. The sci-tech journals of university must be reformed, and the measures that editors must take to cope with the challenges are as follows.

\section{Measures of editors to challenges}

\subsection{Establishing brand awareness and improving the competitiveness of journals}

In the new era, the number of the sci-tech journals is on the rapid rise and more kinds of journals of the same discipline come into being. Therefore, authors and readers can only select those high-quality, unique, informative and high-profile journals. Therefore, there exists competitive situation in sci-tech journal market. The key to winning in the competition is the quality and brand, and the quality and brand are the backbone of the future market. At present, China's publishing industry has been growing awareness of the importance of brand. If the editors don't have the brand awareness or strengthen and create brand, the journals can not win in the fierce competition in the market. Creating brands and building quality are the fundamental way to achieve social and 
economic benefits for sci-tech journals. To create a brand, the first problem to solve is the brand positioning. Only accurate positioning can help creating competitive journals, and competitive journals are the basis and prerequisite of brand. Excellent journals are periodicals with good quality in both the internal and external. To create competitive journals, the most important is carefully selecting topics, organizing manuscripts, reviewing, and editing, typesetting, proofreading, cover designing and printing. Besides, to create brands, the reform and innovation must be carried out in creating the possession, excellence, novelty and uniqueness [3]. For example, Journal of Jilin Agricultural University has established its characteristic columns and also created its own brand.

\subsection{Enhancing awareness of standardization and accelerating the internationalization}

For a long time, the mode of editing and publishing sci-tech journals in their own way results in the different format arrangement systems. On the occasion of sharing information resources of the science and technology world widely, standardization of sci-tech journals is particularly important. This is due to the standardization of breaking through the restrictions of time, space, language and writing, which paves the way to the development of human and technological exchanges. The more science and technology develops, the greater it needs for the standardization. Standardization is the premise and foundation of the internationalization of sci-tech journals [4,5]. To achieve standardization is to implement international standards, national standards and legal unit of measurement. The core standardization of sci-tech journals is the standardization of the format. Firstly, the format and size should be standardized, which is related to the practicability, aesthetic, communication and storage of journals. Secondly, the serial number and bar code should be standardized, which plays an important role in accelerating the process of internationalization of sci-tech journals. Thirdly, the legal units of measurement and terms should be widely used, which benefits international academic exchange and application, also benefits the advancement and development of science and technology [6]. Fourthly, chart layout and references should be standardized internationally, especially in English abstract, English version of journals should be in line with international practice, which requires editors of sci-tech journals to understand and master the domestic and international new scheduling standards and norms, also to improve their foreign language levels, especially English to become standardized, normalized and international editors.

\subsection{Establishing a sense of further processing of information and speeding up the dissemination of scientific and technical information}

In the new era, traditional working mode of editors of sci-tech journals must be reformed because the channel that people obtain scientific and technical information has undergone major changes. The traditional basic function of sci-tech journals is to mainly publish scientific and technical papers, and to carry out a serious of activities such as editing, typesetting, proofreading, printing, publishing and distributing etc., revolving around the papers. Therefore, editors often content with the work of arranging and typesetting according to the manuscripts because authors assume responsibility for their own papers which can not reveal information resources of scientific and technical papers from multiple perspectives. From a macro point of view of scientific and technical research, if the editing work can not produce new knowledge and information, it can only serve as a source of information for scientific and technical work, as a second position of scientific and technical research work [7]. In the new era, mankind has entered the information age, and scientific and technical information in the information age plays a decisive role for society in capital, resources, etc. Those who own information and develop the most, the deepest and the most recent information can grasp the initiative in competition. Therefore, when the editors of sci-tech journals edit scientific and technical papers, they must go into the paper's research background, current situation, theories, objects, methods and even microenvironments like data and formulas, etc. to offer a variety of information from many aspects, such as funded projects, brief introduction of authors, structured abstract, keywords, introduction, discussion etc., which can improve informational function and index function of sci-tech journals of university. In order to meet the readers' needs, these functions can produce more comprehensive information, accelerate the dimension of information and save readers' time for information index, which can improve the influence of sci-tech journals of university. 


\subsection{Establishing editors' modern awareness and improving the applying ability of the new media}

The new media age offers the traditional sci-tech journals and editing tools with a new vitality and meaning, which brings unprecedented challenges to editors of sci-tech journals of university. Moreover, with the development of new media technologies the challenges become urgent. Therefore, editors must change their concepts, strengthen the sense of times and urgency, set up editors' modern awareness and improve the ability to accept new things. This requires editors not only have the qualities and abilities in the traditional sense, but also add, update and optimize the knowledge structure, and strive to learn modern editing theories and techniques to improve the ability to capture information and capabilities of applying new media [8]. In addition, editors should also have some research capability. This is the requirement for reviewing, identifying and selecting manuscripts $[9,10]$. Because sci-tech journals of university are highly professional, editors without professional knowledge and research ability have no voice on manuscripts and can not edit high quality of sci-tech journals.

\subsection{Enhancing management consciousness and improving benefits of journals}

The sci-tech journals will be marketed as a special commodity in the new era. After entering the market of sci-tech journals, how to develop healthily, how to adhere to the purpose of founding journals and how to play its role in the spread of scientific and technological achievements better is a new topic faced by the editors of sci-tech journals. This requires the journal editors to set up the concept of benefits, enhance the sense of management, actively participate in the management of journals and improve the market competitiveness of journals. The editors should learn the advanced management ideas and modes, and strive to make their own editing and publishing journals high quality, low cost, fast issue and more subscribers. In the premise of ensuring social benefit, the editors should strive to create economic benefit. It is worth noting that the sci-tech journals must always put social benefit in the first place. When the contradiction between them happens, the economic benefit should be subject to social benefit. At the same time, the editors should realize that the social and economic benefits of journals are dialectical unity. They are interdependent, mutually promoting, and can be transformed into each other. Social benefit of journals is outstanding, improving its reputation, expanding its influence, attracting more readers and writers to increase subscribers and circulation, which results in obtaining good economic benefit, adding equipment, improving the running condition and arousing editor working enthusiasm. Meanwhile, the journals can attract more excellent manuscripts so that the quality of journals can be improved further. As such, both social and economic benefits can be obtained.

\subsection{Enhancing the copyright awareness and protecting the legitimate rights and interests}

With China's entering the WTO and economic globalization, China's copyright protection system has been gradually established and improved. However, due to the lack of awareness of copyright in many years, there are still many problems in the protection of copyright, especially the copyright protection of sci-tech journals. With the development of economic globalization, people's right awareness is increasing gradually. Only when scientific and technical information is lawfully and orderly spread it can produce real benefits $[11,12,13]$. Therefore, the editors of journals should set up the consciousness of copyright. First, the editors should study the copyright law to constantly enhance self-protection awareness by means of self-study and centralized study. Then, the editors should take various forms of giving publicity to the copyright law, such as using the network and the media to publicize the importance of copyright protection, introduce relevant laws, regulations and related cases, and holding copyright knowledge lectures and seminars etc. Moreover, the editorial department of scientific and technical periodicals should sign the contract with authors in order to respect and protect the legitimate rights and interests of the authors, at the same time, and protect the legitimate rights and interests of the periodical editorial department.

\subsection{Enhancing publicity awareness and improving the influence of journals}

The human race has entered a new information era, and the competition among journals is fierce in the new era. After being published, if any kind of journals doesn't promote or publicize its own, it is difficult to be recognized by the majority of readers and authors and the journals will not be 
concerned about. Therefore, to expand the academic influence of the journals, improve their reputation, accelerate the process of internationalization, it is necessary to increase publicity efforts, strengthen the communication and cooperation with excellent journals at home and abroad, and strive to enter more and more important domestic and international retrieval systems and databases. First, the editors of sci-tech journals should offer their current periodicals to the domestic and foreign libraries, universities, the research institutes of the related subject and the document retrieval institution. Second, they try to participate in the academic conferences at home and abroad, and publicize or offer their own academic journals to the people attending the conference, which makes more people, understand the existence and development of the journal. Third, it is a quick, intuitive and economical way to promote the journal through the web [14].

\section{Conclusion}

In short, the new media age brings opportunities and challenges to the editors of sci-tech journals of university. This requires the editors to change the consciousness, to renew the idea, to develop the ability, to broaden the field of vision, to supplement and update the professional knowledge, to improve the professional skills and to actively participate in various forms of continuing education and professional training[15,16].The editors should study computer technology, network technology and multimedia technology to master the modern editing skills and improve the comprehensive qualities and abilities, so they can edit and publish sci-tech journals by means of modernization, promoting the development of the journals and new media convergence.

\section{References}

[1]. Zhang Min \& Feng Jing. Characteristics of the New Media age and Its Influence on China [J]. West Leather, 2016 (4):114.(In Chinese)

[2]. Bai Xiuyun. Reflection on the Cultivation of College Journal Editors' quality in the New Era [J]. Journal of Chifeng University, 2016,32 (3) :171-172. (In Chinese)

[3]. Hu Chuanzhuo. Journal of Modern Science and Technology [M].Changsha: Journal of Modern Science and Technology, 2001:81-97,360-363. (In Chinese)

[4]. Zhang Xingyong, Jiang Xinzheng \& Li Mingde. Standardization, normalization and internationalization of sci-tech periodicals[J].Chinese Journal of Scientific and Technical Periodicals,2003,14 (Special Issue) :740 (In Chinese)

[5]. Wei Xiuping. The Existing Problems and Future Development Trend of Chinese Sci-tech Periodicals [J]. Chinese Journal of Scientific and Technical Periodicals 2001,12 (S) :1-3. (In Chinese)

[6]. Weng Yongqing. Format of Scientific and Technological Periodical-Standardization and Normalization[M]// Wang Liming. Editing Tutorial of Sci-tech Periodicals. Beijing: People's Military Medical Press, 1999 :37 (In Chinese)

[7]. Fu Xingkui. Research on Development of Science and Information Characteristics of Scientific and Technical Journal[J].Journal of Jilin Agricultural University, 1995,17 (S) :148-150. (In Chinese)

[8]. Yang Rongjun. On Improvement of the of Editors' Quality of Journal in the Era of Network Digitalization[J]. Journal of Suzhou University of Science and Technology (Social Science), 2010,27(6):94-96. (In Chinese)

[9]. Zhu Junhua. Quality and Capability the Editors Should Possess in Modern Journals of Colleges [J]. Journal of Ningbo University(Natural Science \& Engineering Edition), 2004,17(2):236-239. (In Chinese) 
[10]. Zheng Ying. On Qualities of the Editors and the Ways to Improve Their Qualities in Colleges and Universities [J]. Journal of Inner Mongolia University for Nationalities (Social Sciences), 2013, 39(6):106-109. (In Chinese)

[11]. Zhao Aiqun \& Zhao Lihua. Study on status and further tactics of protecting sci-tech periodical copyrights [J]. Acta Editologica, 2002,14(3):168-169. (In Chinese)

[12]. Cheng Jinyuan. Discussion on periodical press and copyright protection [R]. Copyright Law Lecture, Beijing:2001. (In Chinese)

[13]. Li Xiangrong. Deep Thoughts of Improving the Quality of Scientific and Technical Journals

[J]. Chinese Journal of Scientific and Technical Periodicals, 2003,14 (Special Issue) :864. (In Chinese)

[14]. He Ping. Necessity of International Development of Biological Science Journals and Its Main Way [J]. Chinese Journal of Scientific and Technical Periodicals, 2003,14(Special Issue) :787. (In Chinese)

[15]. Shen Yinan, Cao Bing \& Tong Jianguo. Cultivation of young editors of sci-tech periodicals in the New Period[J]. Acta Editologica, 2014, 26 (1):79-82. (In Chinese)

[16]. Zheng Xiaomei \& Tong Jianguo. Four points of view of professional qualities cultivation for young editors of sci-tech journals[J]. Acta Editologica, 2012,24 (2):178-179. (In Chinese) 